\title{
NEFA-Sensitive Orai1 Expression in Regulation of De Novo Lipogenesis
}

\author{
Bingbing Zhang ${ }^{a}$ Wei Yang ${ }^{b}$ Ying Zou ${ }^{b}$ Ming Lib Han Guo ${ }^{b}$ Hongyou Zhang ${ }^{b}$ \\ Cheng Xia ${ }^{\mathrm{b}}$ Chuang $\mathrm{Xu}^{\mathrm{b}}$ \\ ${ }^{a}$ College of Life Science and Technology, Daqing, ${ }^{b}$ College of Animal Science and Technology, \\ Heilongjiang Bayi Agricultural University, Daqing, China
}

\author{
Key Words \\ $\mathrm{NEFA} \cdot$ De novo lipogenesis $\bullet$ Orai1 $・ \mathrm{NFKB}$
}

\begin{abstract}
Background/Aims: Non-esterified fatty acids (NEFAs) are important inducers of inflammatory responses and hepatic lipid accumulation, which lead to non-alcoholic fatty liver disease (NAFLD). High plasma NEFA is found in NAFLD patients, and associated with metabolic syndrome and type-2 diabetes. NFKB is known to upregulate Orai1, the $\mathrm{Ca}^{2+}$ channel responsible for storeoperated $\mathrm{Ca}^{2+}$ entry. The present study explored the role of NEFA-sensitive NFKB-dependent Orai1 expression in the regulation of lipid synthesis. Methods: BRL-3A rat liver hepatocyte lines were studied in the absence and presence of NEFA. Transcript and protein expression levels of factors involved in lipid synthesis were quantified by quantitative polymerase chain reaction (qPCR) and western blot analyses. Fatty acids were measured by immunofluorescence. Results: NEFA significantly increased, as indicated by the expression of sterol regulatory element-binding protein 1 (SREBP-1C), fatty acid synthase (FAS), acetyl-CoA carboxylase $\alpha$ (ACC1), Orai1, and NFkB p65 by qPCR and western blot analyses. These effects were reversed by the Orail inhibitor, 2-aminoethoxydiphenyl borate, and the NFKB inhibitor, wogonin. Furthermore, SREBP-1C, FAS, $A C C 1$, and Orai1 were significantly decreased by Orai1 silencing. Conclusions: Taken together, these results demonstrated that NEFA-sensitive NFKB-dependent Orail expression regulates de novo lipogenesis.

\section{Introduction}

Non-alcoholic fatty liver disease (NAFLD) is a very common disorder characterized by excessive lipid deposition in hepatocytes (steatosis) with no alcohol consumption [1]. NAFLD contributes significantly to morbidity and mortality associated with obesity, type 2 diabetes, and metabolic syndrome [2,3]. NAFLD involves increased hepatic fatty acid synthesis, decreased fatty acid catabolism [4], and cellular stress, including oxidative stress [5], inflammatory/immune responses, and endoplasmic reticulum stress [6].

B. Zhang and W. Yang contributed equally to this work. 
Normally, non-esterified fatty acids (NEFAs) and triglycerides (TGs) are increased in the plasma of NAFLD patients. The major NEFAs include palmitic, palmitoleic, stearate, oleic, and linoleic acids [7-9]. Previous studies have reported that single fatty acids can influence lipid accumulation. In the present study, a high concentration of NEFAs was prepared to approximate the composition and concentration of circulating NEFAs. Fatty acids in the liver used for TG synthesis are provided by the diet, adipose tissue lipolysis, or de novo lipogenesis [10]. Previous reports indicate that sterol regulatory element-binding protein 1 (SREBP-1c), acetyl-CoA carboxylase $\alpha$ (ACC1), and fatty acid synthase (FAS) were important factors in de novo lipogenesis [11-13]. However, the mechanisms underlying the regulation of lipid metabolic pathways in the setting of NAFLD have only been partially elucidated. Recent observations showed that lipid accumulation in chronic obesity is stimulated by cytosolic $\mathrm{Ca}^{2+}$ concentrations $\left(\left[\mathrm{Ca}^{2+}\right]_{\mathrm{i}}\right)$ in the livers of Zucker rats, and that store-operated calcium entry (SOCE) was involved in regulating metabolism [14-16]. A better understanding of the regulation of lipid metabolism in steatotic hepatocytes will provide insight that could lead to the development of new therapeutic strategies for the control of NAFLD.

To the best of our knowledge, the role of the cytosolic $\left[\mathrm{Ca}^{2+}\right]_{\mathrm{i}}$ in lipid accumulation of NAFLD, especially in de novo lipogenesis, remains unknown. In some cell types, $\mathrm{Ca}^{2+}$ may enter through SOCE, which is accomplished by the 4-transmembrane-spanning pore forming calcium release-activated channel moiety Orai1 [17-19]. Orai1 has previously been shown to be regulated by nuclear factor NFKB [20,21].

In patients with NAFLD and type 2 diabetes, excessive amounts of TGs are deposited in hepatocytes leading to steatosis and the activation of the $N F \kappa B$ pathway [22]. The present study explored whether NEFA induces de novo lipogenesis on BRL-3A cells and, if so, whether the effect involves NFkB-sensitive Orai1 expression.

\section{Materials and Methods}

\section{Cell culture}

BRL-3A rat liver cells were cultured in high-glucose Dulbecco's modified Eagle's medium (DMEM) supplemented with $10 \%$ fetal calf serum and $1 \%$ penicillin/streptomycin under standard culture conditions. Cells were pretreated with $1.2 \mathrm{mM}$ NEFA preparation for $6 \mathrm{~h}$ after starvation overnight. Then, $50 \mu \mathrm{M}$ Orai1 inhibitor, 2-APB (Tocris Bioscience, Bristol, UK), or $100 \mu \mathrm{M}$ NFkB inhibitor, wogonin (Sigma-Aldrich Corporation, St. Louis, MO, USA), were added for $6 \mathrm{~h}$.

\section{NEFA preparation}

The composition and concentration of NEFAs used in this study were chosen to approximate the concentrations of serum NEFAs [23-25]. The stock NEFA (10 mM) solution included oleic acid (4.35 mM), linoleic acid $(0.49 \mathrm{mM})$, palmitic acid $(3.19 \mathrm{mM})$, stearic acid $(1.44 \mathrm{mM})$, and palmitoleic acid $(0.53 \mathrm{mM})$. Stock NEFA solution was diluted in cell culture medium to achieve a final total NEFA concentration of 1.2 $\mathrm{mM}$.

\section{RNA Silencing}

For silencing, $3 \times 10^{5}$ cells (6-well plate) were seeded $24 \mathrm{~h}$ before the experiment and then transfected with 40 pM rat Orai1 siRNA (Shanghai GenePharma Co., Ltd., Shanghai, China) or non-targeting siRNA (Shanghai GenePharma Co., Ltd.) using siRNA-Mate transfection reagent (Shanghai GenePharma Co., Ltd.) according to the manufacturer's protocol.

Quantification of mRNA expression

Total RNA was isolated with Trizol RNA extraction reagent (Invitrogen Corporation, Carlsbad, CA, USA); mRNA was transcribed with Reverse Transcriptase M-MLV (RNase H-) (Takara Bio, Inc., Otsu, Japan) using an oligodT primer. Quantitative RT-PCR was performed on a BioRad iCycler iQTM Real-Time PCR Detection System (Bio-Rad Laboratories Inc., Hercules, CA, USA).

The qPCR reaction mixture contained $2 \mu \mathrm{l}$ of cDNA, $1 \mu \mathrm{M}$ of each primer, $10 \mu \mathrm{l}$ of FastStart Universal 


\title{
Cellular Physiology Cell Physiol Biochem 2018;47:1310-1317 \begin{tabular}{c|c|c|} 
DOI: 10.1159/000490226 & O 2018 The Author(s). Published by S. Karger AG, Basel \\
www.karger.com/cpb
\end{tabular} Zhang et al.: Orai1-Dependent Regulation of De Novo Lipogenesis
}

SYBR Green Master (F. Hoffmann-La Roche AG, Basel, Switzerland), and sterile water for a final volume of 20 $\mu \mathrm{l}$; qPCR conditions were $95^{\circ} \mathrm{C}$ for $3 \mathrm{~min}$, followed by 40 cycles at $95^{\circ} \mathrm{C}$ for $10 \mathrm{~s}$ and $58^{\circ} \mathrm{C}$ for $30 \mathrm{~s}$. Calculated mRNA expression levels were normalized to the expression levels of TATA box-binding protein (Tbp) of the same cDNA sample. Gene expression was quantified with the $2^{-\Delta \Delta C T}$ method.

The following primers were used:

Rat Tbp (TATA box-binding protein):

forward (5'-3'): ACTCCTGCCACACCAGCC

reverse (5'-3'): GGTCAAGTTTACAGCCAAGATTCA

\author{
Rat Orai1 \\ forward ( $\left.5^{\prime}-3^{\prime}\right)$ : CGTCCACAACCTCAACTCC \\ reverse (5'-3'): AACTGTCGGTCCGTCTTAT \\ Rat Srebp-1c \\ forward ( $5^{\prime}-3^{\prime}$ ): GACGACGGAGCCATGGATT \\ reverse (5'-3'): GGGAAGTCACTGTCTTGGTTGTT
}

Rat Fas1

forward (5'-3'): CTATTGTGGACGGAGGTATC

reverse (5'-3'): TGCTGTAGCCCAGAAGAG

\section{Rat ACC1}

forward (5'-3'): TGAGGAGGACCGCATTTATC

reverse (5'-3'): AAGCTTCCTTCGTGACCAGA

\author{
Rat NFKB $p 65$ \\ forward ( $5^{\prime}-3^{\prime}$ ): TTCCCTGAAGTGGAGCTAGGA \\ reverse (5'-3'): CAGTCGAGGAAGACACTGGA
}

\section{Western blot analysis}

Orai1, NFKB p65, SREBP-1c, FAS and ACC1 relative protein abundances were determined in BRL-3A rat liver cells. The cells were washed in ice-cold PBS. RIPA lysis buffer (Beyotime Biotechnology, Shanghai, China) was added to solubilize the cells. Samples were incubated on ice for $30 \mathrm{~min}$ and then centrifuged at $14,000 \mathrm{rpm}$ and $4^{\circ} \mathrm{C}$ for $20 \mathrm{~min}$. The supernatant was removed and used for Western blotting. Total protein $(40-60 \mu \mathrm{g})$ was separated by SDS-PAGE, thereafter transferred to PVDF membranes and blocked in 5\% non-fat milk/Tris-buffered saline/Tween-20 (TBST) at room temperature for 1 hour. Membranes were probed overnight at $4^{\circ} \mathrm{C}$ with polyclonal rabbit or mouse antibodies against Orai1, SREBP-1c, ACC1, FAS, or NFKB p65 (1:700 to 1:1000 in TBS containing 5\% BSA and Tween 20). After incubation with HRPlabeled goat anti-rabbit or mouse secondary antibody (Beyotime Biotechnology, 1:2000) for 1 hour at room temperature, bands were visualized with enhanced chemiluminescence reagents (Beyotime). Membranes were also probed with $\beta$-Actin antibody (Cell signaling, 1:2000) as loading control. Densitometric analyses were performed using Image J software.

\section{$T G$ content assay}

After treatments, the cells were collected. The TG content in BRL-3A cells was determined using an enzymatic method with the TG assay kit (Applygen Technologies Inc., Beijing, China) in accordance with the manufacturer's instructions.

\section{Lipid droplet fluorescence assay}

BRL-3A cells were treated with $1.2 \mathrm{mM}$ NEFA for 6 , 9, or $12 \mathrm{~h}$ for assessment of lipid droplet fluorescence by cellular staining with BODIPY 493/503 (Invitrogen Corporation) according to the manufacturer's instructions. Coverslips were mounted with glycerinum and images were obtained with a confocal laserscanning microscope (Leica TCS SP8; Leica, Wetzlar, Germany) with 40×/1.3 NA differential interference contrast and analyzed with the instrument's software.

\section{KARGER}




\section{Cellular Physiology Cell Physiol Biochem 2018;47:1310-1317

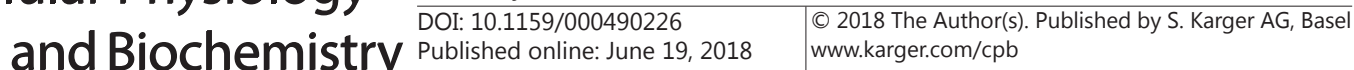 \\ Zhang et al.: Orai1-Dependent Regulation of De Novo Lipogenesis}

Statistical analysis

Data are presented as the means \pm standard error of the mean (SEM) with $n$ representing the number of independent experiments. All data were tested for significance with the unpaired Student's $t$-test or oneway analysis of variance (ANOVA) followed by the Tukey post-hoc test. A probability $(p)$ value of $<0.05$ was considered statistically significant.

\section{Results}

The present study explored hepatocyte de novo lipogenesis in the presence of high concentrations of NEFA and the involvement of NFKB and Orai1 in this process.

We first investigated the effect of high-concentration NEFA on lipid accumulation and secretion in BRL-3A cells. As illustrated in Figs. 1A and 1B, incubation with 1.2 mM NEFA for 12 $\mathrm{h}$ caused extensive lipid droplet formation and increased TG synthesis (Fig. 1C).

The next series of experiments explored whether SOCE via Orai1 and NFkB p65 are induced in BRL-3A cells in response to NEFA, and therefore may participate in the regulation of

Fig. 1. Effect of high concentration NEFA on lipid accumulation in BRL-3A cells. A. Representative immunofluorescence images demonstrating nuclear staining (DAPI, Blue; left images), lipid droplets staining (Green; middle images), and an overlay of both (merge, right images) in BRL-3A cells incubated without or with different time NEFA (1.2 $\mathrm{mM})$. B. Arithmetic means \pm SEM $(n=3)$ of lipid droplets value (relative to control) in BRL-3A cells incubated without or with different time NEFA (1.2 mM). C. Effects of NEFA (1.2 mM, 12h) on TG synthesis in BRL-3A cells. ${ }^{* *}(\mathrm{p}<0.01)$, $* * *(\mathrm{p}<0.001)$ indicate difference from control (t-test).

Fig. 2. Effect of high concentration NEFA on Orai1, p65 in BRL-3A cells. A. Arithmetic means \pm SEM $(n=12)$ of Orai1 and NF $\kappa B$ p 65 mRNA abundance (relative to Tbp mRNA) in BRL-3A cells incubated without (white bar) or with (black bar) NEFA (1.2 mM, 12h). B. Representative western blots showing the protein expression of Orai1, NFKB p65 and $\beta$-actin in BRL-3A cells incubated without or with NEFA (1.2 mM, 12h). C. Arithmetic means \pm SEM $(n=6)$ of the Orai $1 / \beta$-actin and $N F \kappa B$ p $65 / \beta$-actin ratios in BRL-3A cells incubated without (white bar) or with (black bar) NEFA (1.2 mM, 12h).
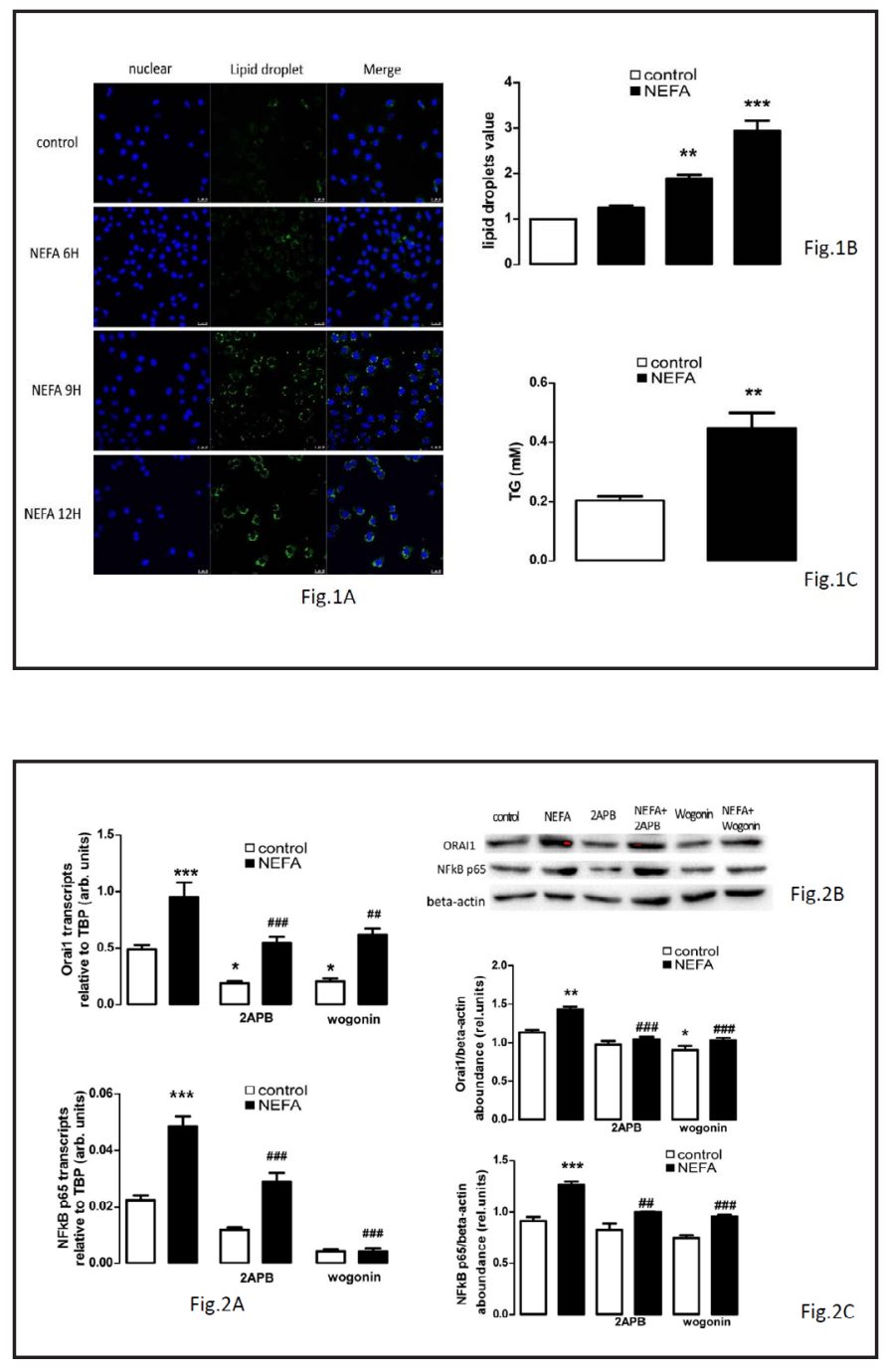
$*(\mathrm{p}<0.05), * *(\mathrm{p}<0.01),{ }^{* * *}(\mathrm{p}<0.001)$ indicate difference from control. \# $(\mathrm{p}<0.05)$, \#\# $(\mathrm{p}<0.01)$, \#\#\# $(\mathrm{p}<0.001)$ indicate difference from NEFA alone (one-way ANOVA). 
Fig. 3. Effect of Ionomycin and Orai1 silencing on de novo lipogenesis in BRL3 A cells. A. Arithmetic means \pm SEM of Srebp-1c, Fas and ACC1 mRNA transcription (relative to Tbp mRNA) in BRL$3 \mathrm{~A}$ cells incubated without (white bars) or with (black bars) Orai1 inhibitor 2APB (100 nM, 6h, n=12), (grey bars) NFкB inhibitor Wogonin (500 nM, 6h, n=12 ), respectively. B. Arithmetic means \pm SEM of Srebp-1c and Orai1 mRNA transcription (relative to Tbp mRNA) in BRL-3A cells incubated without (white bars) or with (black bars) siOrai1. C. Representative western blots showing the protein expression of SREBP-1c, FAS and ACC1, Orai1, NFKB p65 and $\beta$-actin in BRL-3A cells incubated without (Si-NO) or with siOrai1. D. Arithmetic means \pm SEM of Srebp-1c, and Fas mRNA transcription (relative to Tbp mRNA) in BRL-3A cells incubated without (white bars) or with (black bars) ionomycin (100 nM, 2 h, n=15). E. Representative western blots showing the protein expression of SREBP-1c, FAS and ACC1 and $\beta$-actin in BRL-3A cells incubated without or with ionomycin (100 nM, $2 \mathrm{~h}, \mathrm{n}=9) \cdot{ }^{*}(\mathrm{p}<0.05)$, $* *(\mathrm{p}<0.01), * * *(\mathrm{p}<0.001)$ indicate significant difference (t-test).

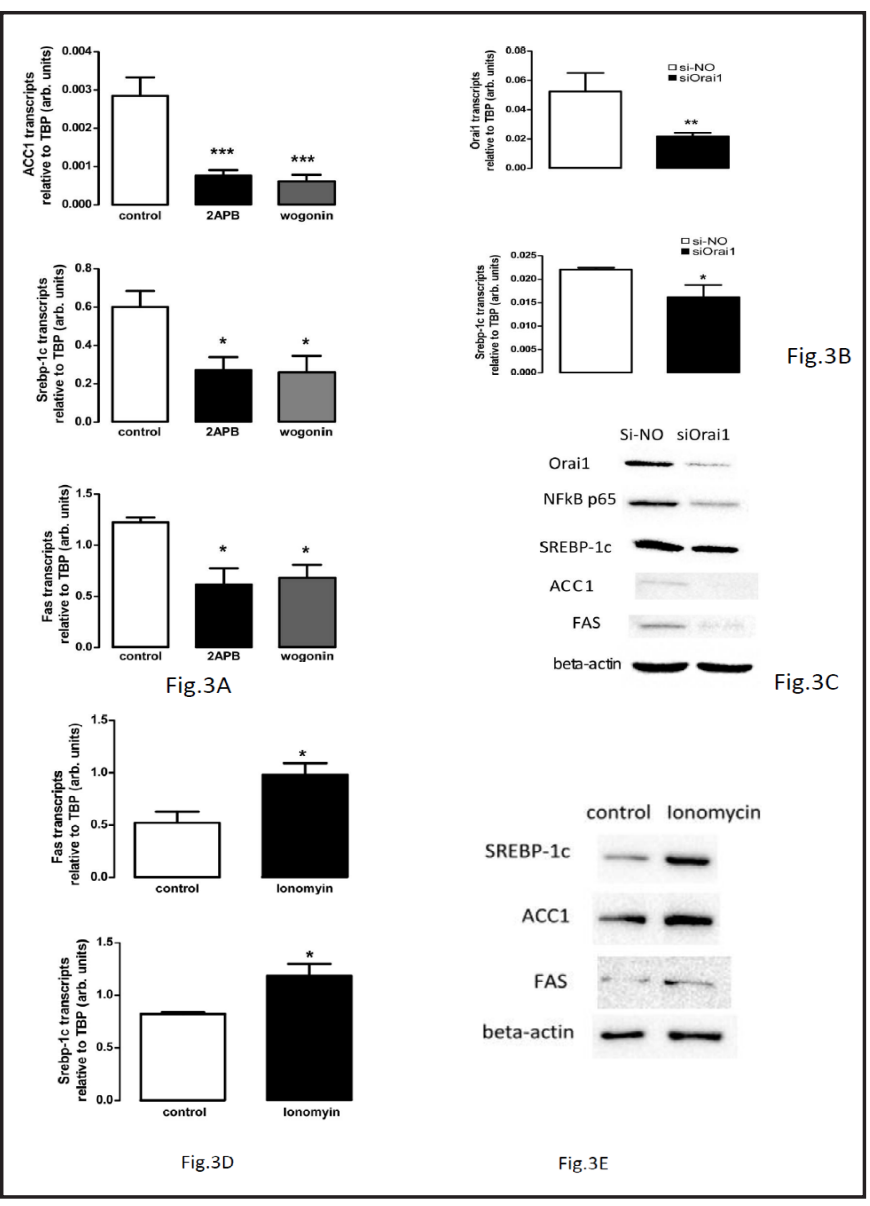

Fig.3

de novo lipogenesis. As illustrated in Fig. 2, expressions of mRNA and protein of Orai1 and NFKB p65 were dramatically up-regulated by NEFA treatment and these effects were reduced by the Orai1 inhibitor, $2 \mathrm{APB}$, and the NFKB inhibitor, wogonin. Moreover, transcription levels of SREBP-1c, ACC1, and FAS were significantly reduced by both 2APB and wogonin, respectively (Fig. 3A). As illustrated in Figs. 3B and 3C, mRNA and protein levels of de novo lipogenesis were significantly decreased by siOai1. To verify the silencing efficiency, Orai1 transcript and protein levels were quantified, which showed that both were dramatically decreased in cells transfected with siOrai1. Furthermore, mRNA and protein levels of de novo lipogenesis were significantly increased by the $\mathrm{Ca}^{2+}$ ionophore ionomycin (Figs. 3D and 3E)

Finally, we determined whether SOCE and/or NFKB are required for lipid accumulation in the presence of high NEFA concentrations. Since Orai1 entry into BRL-3A cells could be attenuated by the NFKB inhibitor wogonin, we tested whether de novo lipogenesis was also $\mathrm{NF} \kappa \mathrm{B}$-sensitive. Indeed, the transcript and protein levels of SREBP-1c, ACC1, and FAS were reduced by the $\mathrm{NF} \kappa \mathrm{B}$ inhibitor wogonin and the Orai1 inhibitor 2APB (Fig. 4).

\section{Discussion}

The present observations disclose a decisive role of NFKB-Orai1 on de novo lipogenesis. The results showed that high concentrations of NEFA promoted de novo lipogenesis, which resulted in abnormal hepatic lipid accumulation. According to the present observations, the transcript and protein expression levels of SREBP-1c, ACC1, and FAS were dramatically increased by NEFA 


\begin{abstract}
Fig. 4. Effect of NEFA on de novo lipogenesis in BRL-3A cells with or without presence of 2-APB and Wogonin. A. Arithmetic means \pm SEM $(\mathrm{n}=12)$ of Srebp1c, Fas and ACC1 mRNA abundance (relative to Tbp mRNA) in BRL$3 \mathrm{~A}$ cells incubated without (white bars) or with (black

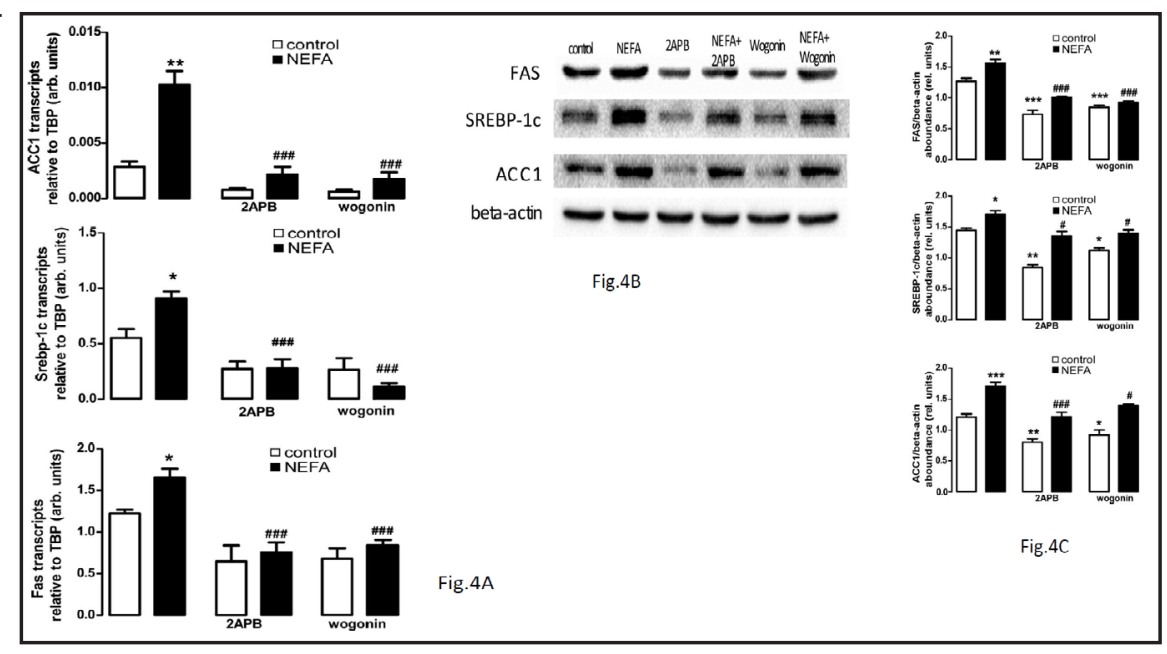
bars) NEFA (1.2

$\mathrm{mM}, 12 \mathrm{~h}$ ) in the absence (left bars) or presence (right bars) of Orai inhibitor 2-APB (100 nM) or of NFkB inhibitor Wogonin (500 nM). B. Representative western blots showing the protein expression of SREBP-1c, FAS and ACC1 and $\beta$-actin in BRL-3A cells incubated without (white bar) or with (black bar) NEFA (1.2 mM, $12 \mathrm{~h}$ ) in the absence (left bars) or presence (right bars) of Orai inhibitor 2-APB (100 nM) or of NFkB inhibitor Wogonin $(500 \mathrm{nM})$. C. Arithmetic means \pm SEM $(\mathrm{n}=6)$ of the SREBP-1c/ $\beta$-actin, FAS $/ \beta$-actin and ACC1 $\beta$ actin ratios in BRL-3A cells incubated without (white bar) or with (black bar) NEFA (1.2 mM, 12h) in the absence (left bars) or presence (right bars) of Orai inhibitor 2-APB (100 nM) or of NFKB inhibitor Wogonin

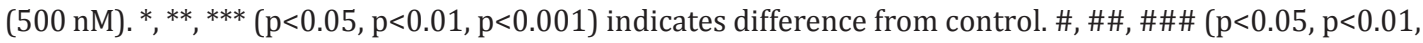
$\mathrm{p}<0.001$ ) indicates difference from NEFA alone (one-way ANOVA).
\end{abstract}

treatment during starvation. These effects were virtually abrogated by the inhibition of NFKB and Orai1. The present observations do not rule out involvement of further signals triggered by the NFKB-Orai1 pathway. The regulation of de novo lipogenesis by NFkB-Orai1 is expected to influence cellular ionic metabolism.

The present study also showed that transcript and protein expression levels of SREBP-1c, ACC1, and FAS were significantly increased by ionomycin, but decreased by siOrai1, indicating that Orai1 may contribute to de novo lipogenesis by promoting the transfer of $\mathrm{NF \kappa B} \mathrm{p65,} \mathrm{which}$ results in the release of pro-inflammatory factors and subsequent induction of liver injury. Indeed, saturated fatty acids can activate the NFKB pathway. Moreover, oleic acid or starvation can induce SOCE and maintain a sustained elevation in intracellular $\mathrm{Ca}^{2+}$ levels $[16,26]$.

SREBP-1c, a membrane-bound transcription factor, promotes TG secretion and lipid droplet formation by stimulating expression of genes involved in fatty acids synthesis. FAS is an important enzyme involved in the de novo synthesis of long-chain fatty acids by converting the acetyl-CoA into palmitate, which is subsequently esterified into TGs in the liver. When energy is available, hepatic fatty acids are esterified into glycerol and stored as triacylglycerol or secreted as very low-density lipoproteins. ACC, the rate-limiting enzyme that catalyzes the carboxylation of acetyl-CoA to form malonyl-CoA, is the pivotal enzyme in the biosynthesis of long-chain fatty acids [27]. Previous studies have shown that dietary fat causes synthesis of hepatic fatty acid synthesis, including SREBP-1c, ACC1, and FAS [28]. Moreover, the impairment of lipid metabolism via the inflammatory signaling of toll-like receptor 4 and NFKB has been reported in high fat diet-induced NAFLD [29]. High concentration NEFA causes several inflammatorybased diseases, such as cardiovascular disease, diabetes, and NAFLD by regulating de novo lipogenesis [30,31]. In view of the present observations, it is tempting to speculate that the remarkable increase in de novo lipogenesis by high dietary fat or starvation results from NFKBdependent SOCE via Orai1. 


\section{Cellular Physiology Cell Physiol Biochem 2018;47:1310-1317 \begin{tabular}{l|l} 
and Biochemistry Published online: June 19, 2018 & $\begin{array}{l}\text { D) 2018 The Author(s). Published by S. Karger AG, Basel } \\
\text { www.karger.com/cpb }\end{array}$ \\
\hline
\end{tabular}

Plasma NEFA, as the major source of fatty acids for TG synthesis, causes abnormal lipid accumulation, which leads to the development of NAFLD [32, 33]. In the present study, the content of TG was measured with an enzyme-linked immunosorbent assay, which indicated that NEFA stimulated TG synthesis and secretion or insulin resistance, resulting in the accumulation of TG. Hence, the NFKB-Orai1 pathway may contribute to TG accumulation.

In conclusion, the present study demonstrated for the first time the involvement of NEFAsensitive NFKB-Orai1 signaling in the regulation of de novo lipogenesis in BRL-3A cells, which included SREBP-1c, FAS, and ACC1.

\section{Acknowledgements}

The study was supported by grants from the National Natural Science Foundation of China (grant nos. 31702308 and 31502133).

\section{Disclosure Statement}

The authors of this manuscript have no conflict of interests to declare.

\section{References}

1 Weiss J, Rau M, Bantel H, Bock H, Demir M, Kluwe J, Krawczyk M, Pathil-Warth A, Schattenberg JM, Tacke F, Roeb E, Geier A, Klinische Studiengruppe N: first data concerning the medical supply of patients with non-alcoholic fatty liver disease in germany - a survey in university hospital centers of hepatology. Z Gastroenterol 2015;53:562-567.

-2 Engin A: Non-alcoholic fatty liver disease. Adv Exp Med Biol 2017;960:443-467.

-3 Vergani L: Fatty acids and effects on in vitro and in vivo models of liver steatosis. Curr Med Chem DOI: 10.21 74/0929867324666170518101334

-4 Jang JE, Park HS, Yoo HJ, Baek IJ, Yoon JE, Ko MS, Kim AR, Kim HS, Park HS, Lee SE, Kim SW, Kim SJ, Leem J, Kang YM, Jung MK, Pack CG, Kim CJ, Sung CO, Lee IK, Park JY, Fernandez-Checa JC, Koh EH, Lee $\mathrm{KU}$ : Protective role of endogenous plasmalogens against hepatic steatosis and steatohepatitis in mice. Hepatology 2017;66:416-431.

5 Gusdon AM, Song KX, Qu S: Nonalcoholic fatty liver disease: Pathogenesis and therapeutics from a mitochondria-centric perspective. Oxid Med Cell Longev 2014;2014:637027.

6 Miyagawa K, Oe S, Honma Y, Izumi H, Baba R, Harada M: Lipid-induced endoplasmic reticulum stress impairs selective autophagy at the step of autophagosome-lysosome fusion in hepatocytes. Am J Pathol 2016;186:1861-1873.

7 Diraison F, Moulin P, Beylot M: Contribution of hepatic de novo lipogenesis and reesterification of plasma non esterified fatty acids to plasma triglyceride synthesis during non-alcoholic fatty liver disease. Diabetes Metab 2003;29:478-485.

8 Hetherington AM, Sawyez CG, Zilberman E, Stoianov AM, Robson DL, Borradaile NM: Differential lipotoxic effects of palmitate and oleate in activated human hepatic stellate cells and epithelial hepatoma cells. Cell Physiol Biochem 2016;39:1648-1662.

-9 Donnelly KL, Smith CI, Schwarzenberg SJ, Jessurun J, Boldt MD, Parks EJ: Sources of fatty acids stored in liver and secreted via lipoproteins in patients with nonalcoholic fatty liver disease. J Clin Invest 2005;115:1343-1351.

10 Hassan K, Bhalla V, El Regal ME, HH AK: Nonalcoholic fatty liver disease: A comprehensive review of a growing epidemic. World J Gastroenterol 2014;20:12082-12101.

11 Siculella L, Tocci R, Rochira A, Testini M, Gnoni A, Damiano F: Lipid accumulation stimulates the capindependent translation of srebp-1a mrna by promoting hnrnp a1 binding to its 5 '-utr in a cellular model of hepatic steatosis. Biochim Biophys Acta 2016;1861:471-481.

12 Samuel VT, Shulman GI: Nonalcoholic fatty liver disease as a nexus of metabolic and hepatic diseases. Cell Metab 2018;27:22-41 


\section{Cellular Physiology Cell Physiol Biochem 2018;47:1310-1317

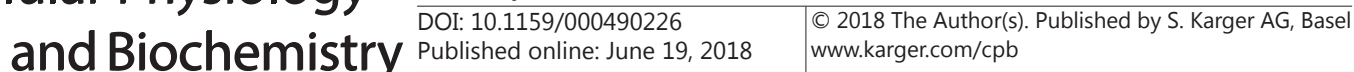

13 Luo DX, Peng XH, Xiong Y, Liao DF, Cao D, Li L: Dual role of insulin-like growth factor-1 in acetyl-coa carboxylase-alpha activity in human colon cancer cells hct-8: Downregulating its expression and phosphorylation. Mol Cell Biochem 2011;357:255-262.

14 Ueta K, O’Brien TP, McCoy GA, Kim K, Healey EC, Farmer TD, Donahue EP, Condren AB, Printz RL, Shiota M: Glucotoxicity targets hepatic glucokinase in zucker diabetic fatty rats, a model of type 2 diabetes associated with obesity. Am J Physiol Endocrinol Metab 2014;306:E1225-1238.

-15 Shiota M, Printz RL: Diabetes in zucker diabetic fatty rat. Methods Mol Biol 2012;933:103-123.

16 Maus M, Cuk M, Patel B, Lian J, Ouimet M, Kaufmann U, Yang J, Horvath R, Hornig-Do HT, ChrzanowskaLightowlers ZM, Moore KJ, Cuervo AM, Feske S: Store-operated $\mathrm{ca}^{2+}$ entry controls induction of lipolysis and the transcriptional reprogramming to lipid metabolism. Cell Metab 2017;25:698-712.

17 Prakriya M, Feske S, Gwack Y, Srikanth S, Rao A, Hogan PG: Orai1 is an essential pore subunit of the crac channel. Nature 2006;443:230-233.

18 Zhang B, Yan J, Umbach AT, Fakhri H, Fajol A, Schmidt S, Salker MS, Chen H, Alexander D, Spichtig D, Daryadel A, Wagner CA, Foller M, Lang F: NFKB-sensitive orai1 expression in the regulation of fgf23 release. J Mol Med (Berl) 2016;94:557-566.

19 Sahu I, Pelzl L, Sukkar B, Fakhri H, Al-Maghout T, Cao H, Hauser S, Gutti R, Gawaz M, Lang F: NFAT5sensitive orai1 expression and store-operated $\mathrm{ca}^{2+}$ entry in megakaryocytes. FASEB J 2017;31:3439-3448.

20 Lang F, Shumilina E: Regulation of ion channels by the serum- and glucocorticoid-inducible kinase sgk1 FASEB J 2013;27:3-12.

21 Lang F, Stournaras C: Serum and glucocorticoid inducible kinase, metabolic syndrome, inflammation, and tumor growth. Hormones 2013;12:160-171.

-22 Ress C, Kaser S: Mechanisms of intrahepatic triglyceride accumulation. World J Gastroenterol 2016;22:1664-1673.

-23 Staff P0: Correction: Comprehensive profiling of plasma fatty acid concentrations in young healthy canadian adults. PloS one 2015;10:e0128167.

24 Abdelmagid SA, Clarke SE, Nielsen DE, Badawi A, El-Sohemy A, Mutch DM, Ma DW: Comprehensive profiling of plasma fatty acid concentrations in young healthy canadian adults. PloS one 2015;10:e0116195.

25 Li P, Liu Y, Zhang Y, Long M, Guo Y, Wang Z, Li X, Zhang C, Li X, He J, Liu G: Effect of non-esterified fatty acids on fatty acid metabolism-related genes in calf hepatocytes cultured in vitro. Cell Physiol Biochem 2013;32:1509-1516.

-26 Dramane G, Abdoul-Azize S, Hichami A, Vogtle T, Akpona S, Chouabe C, Sadou H, Nieswandt B, Besnard P, Khan NA: Stim1 regulates calcium signaling in taste bud cells and preference for fat in mice. J Clin Invest 2012;122:2267-2282.

27 Tanaka M, Kita T, Yamasaki S, Kawahara T, Ueno Y, Yamada M, Mukai Y, Sato S, Kurasaki M, Saito T: Maternal resveratrol intake during lactation attenuates hepatic triglyceride and fatty acid synthesis in adult male rat offspring. Biochem Biophys Rep 2017;9:173-179.

28 Vallim T, Salter AM: Regulation of hepatic gene expression by saturated fatty acids. Prostaglandins Leukot Essent Fatty Acids 2010;82:211-218.

29 Porras D, Nistal E, Martinez-Florez S, Pisonero-Vaquero S, Olcoz JL, Jover R, Gonzalez-Gallego J, GarciaMediavilla MV, Sanchez-Campos S: Protective effect of quercetin on high-fat diet-induced non-alcoholic fatty liver disease in mice is mediated by modulating intestinal microbiota imbalance and related gut-liver axis activation. Free Radic Biol Med 2017;102:188-202.

-30 Patterson E, Wall R, Fitzgerald GF, Ross RP, Stanton C: Health implications of high dietary omega-6 polyunsaturated fatty acids. J Nutr Metab 2012;2012:539426.

31 Cartland SP, Harith HH, Genner SW, Dang L, Cogger VC, Vellozzi M, Di Bartolo BA, Thomas SR, Adams LA, Kavurma MM: Non-alcoholic fatty liver disease, vascular inflammation and insulin resistance are exacerbated by trail deletion in mice. Sci Rep 2017;7:1898.

32 Guzzardi MA, Hodson L, Guiducci L, La Rosa F, Salvadori PA, Burchielli S, Iozzo P: The role of glucose, insulin and nefa in regulating tissue triglyceride accumulation: Substrate cooperation in adipose tissue versus substrate competition in skeletal muscle. Nutr Metab Cardiovasc Dis 2017 ;27:956-963.

-33 Masaki H, Kim N, Nakamura H, Kumasawa K, Kamata E, Hirano KI, Kimura T: Long-chain fatty acid triglyceride (TG) metabolism disorder impairs male fertility: A study using adipose triglyceride lipase deficient mice. Mol Hum Reprod 2017;23:452-460. 